\title{
Ortaokul Öğrencilerine Yönelik Çevre Eğitimi Kavramları Farkındalık Ölçeği: Geçerlik Ve Güvenirlik Çalışması*
}

\section{Yağmur ÖTÜN**，Hüseyin ARTUN***, Atilla TEMUR ${ }^{* * * *}$, İsrafil TOZLU*****}

Öz: Bu çalışmanın amacı; ortaokul öğrencilerinin çevre eğitimi kavramlarına yönelik farkındalık düzeylerini belirlemek için bir ölçek geliştirmektir. Çalışmada nicel yöntemlerden yararlanılmıştır. Çalışmanın örneklemini; Bitlis ili merkez ortaokullarının 6., 7. ve 8. sınıflarında öğrenim gören toplamda 1140 öğrenci oluşturmaktadır. Çalışmada, veri toplama aracı olarak araştırmacılar tarafından geliştirilen 22 maddelik "Çevre Eğitimi Kavramları Farkındalık Ölçeği (ÇEKFÖ)" kullanılmıştır. Ölçeğin faktör yapısı Açımlayıcı Faktör Analizi (AFA) ile belirlenmiş ardından Doğrulayıcı Faktör Analizi (DFA) uygulanmıştır. Ölçeğin Cronbach Alfa iç tutarlılık katsayısı 0.75 olarak hesaplanmıştır. Sonuç olarak, 22 maddeden oluşan 6 faktörlü geçerli ve güvenilir bir ölçek geliştirilmiştir.

Anahtar Kelimeler: Çevre Eğitimi, Farkındalık, Ölçek Geliştirme, Faktör Analizi.

\section{Environmental Education Concepts Awareness Scale for Secondary School Students: A Validity And Reliability Study}

\footnotetext{
${ }^{*}$ Bu çalışma birinci yazarın yüksek lisans tezinden üretilmiştir.

*** Yuzüncü Yıl Üniversitesi, Yüksek Lisans Öğrencisi, Eğitim Bilimleri Enstitüsü, otunyagmur88@ gmail.com **** Yrd. Doç. Dr., Yüzüncü Yıl Üniversitesi, Eğitim Fakültesi, Temel Eğitim Bölümü, Sınıf Öğretmenliği ABD, huseyinartun@gmail.com

***** Doç. Dr., Yüzüncü Yıl Üniversitesi, Eğitim Fakültesi, Matematik ve Fen Bilimleri Eğitimi Bölümü, Fen Bilgisi Eğitimi ABD, temurat@yahoo.com

${ }^{* * * * * *}$ Yrd. Doç. Dr., Yüzüncü Yıl Üniversitesi, Eğitim Fakültesi, Matematik ve Fen Bilimleri Eğitimi Bölümü, Fen Bilgisi Eğitimi ABD, israfiltozlu@gmail.com
} 
http://dx.doi.org/10.23891/efdyyu.2017.20

ISSN:1305-020

Abstract: The aim of this study is to develop a scale in order to define secondary school students' level of awareness about environmental education. Qualitative methods are used in the study. As for the sample of the study, totally 1140 students $\left(6^{\text {th }}, 7^{\text {th }}\right.$ and $8^{\text {th }}$ grades $)$ are included from the central secondary schools of Bitlis city. Data collection tool of the study is "Environmental Education Concepts Awareness Scale (EECAS)", a 22 itemed scale developed by the researchers. Factor structure of the scale is defined by exploratory factor analysis (EFA) and then confirmatory factor analysis (CFA) is applied. The Cronbach Alpha internal coefficient of consistency of the study is calculated as 0.75 . As a result, a valid and reliable scale is developed which is composed of 22 items and 6 factors.

Keywords: Environmental Education, Awareness, Scale Development, Factor Analysis

\section{Giriş}

Yaşadığımız doğal çevre, insanların ekonomik, sosyal, kültürel, sanatsal vb. gibi faaliyetlerinden olumsuz yönde etkilenmektedir. Tarih boyunca insanların bu olumsuz etkilerinin doğal çevrenin aleyhinde geliştiği ve sanayileşme ile birlikte çevre üzerindeki baskının daha da yoğunlaştığı söylenebilir. Özellikle yaşanan büyük çevresel sorunların etkisi ve çevreci hassasiyetleri gelişmiş insanların çalışmaları ile çevreci fikir akımları rağbet görmeye ve kabul edilmeye başlamıştır. Yapılan ulusal ve uluslararası konferanslar yaşanan çevresel sorunların boyutlarını ortaya koyarken çevrenin korunması gerektiği de belirtilmektedir (Özdemir, Yıldız, Ocaktan ve Sarışen, 2004; Eulefeld, 1979; Loubser ve Ferreira, 1992; Şama, 2003). Her kesimden bireyler çevre ve çevrecilik düşüncesine katk1 vermeye ve çevrenin sahibi değil bir parçası olduklarını anlamaya çalışmaktadırlar. Bu nedenle, insanların öncelikle çevrenin efendisi olmadığını idrak etmesi ve geçmişten 
http://dx.doi.org/10.23891/efdyyu.2017.20

ISSN:1305-020

günümüze çevreye verdikleri zararın farkına varmaları gerektiği belirtilmektedir (Kayaer, 2013).

Çevre eğitiminin, çevreye yönelik farkındalık yaratma sürecinde büyük bir öneme sahip olduğu söylenebilir. Çevre eğitimi, çevre problemleriyle ilgili bilgi sahibi olan, bu problemleri çözmede nasıl bir katkısı sağlayabileceğinin ve çevre kavramlarının farkında olan bireyler yetiştirmektir (Xuehua, 2004; Waktola, 2009; Solmaz, 2010). Çevre problemlerinin çözülmesi, insanların problemleri algılaması ve risklerinin farkında olması ile aşılabilecektir (Vaizoğlu ve Altıntaş, 2005). Bu farkındalıklar çevre eğitiminin ne kadar gerekli olduğuna dikkat çekmektedir. İnsanlar çoğu zaman çevreye verdikleri zararın farkında olmamakta veya önemsiz görünen çevre kirliliğinin küresel olarak ne boyutlara ulaşacağını bilmeden yaşamaktadırlar. Dolayısıyla, çevre sorunlarının tanımlanması ve giderilmesi ancak çevre kavramlarının farkına varılması ile mümkündür. Bundan dolayı bireylerin çevre kavramlarına yönelik farkındalık düzeylerinin belirlenmesi ile çevre sorunlarının önleneceği düşünülmektedir. Öğrencilerin çevre kavramlarındaki farkındalıklarının ve ilgilerinin yüksek olması çevre konusunda olumlu davranışlar kazandırmaya yardımcı olacağı söylenebilir. Çevre farkındalığını kazandırmanın bir yolu da çevre ile ilgili kavramların anlaşılmasından geçmektedir (Solmaz, 2010). Çünkü etkili bir çevre eğitimi, kavramlar düzeyinde ele alınarak sağlanabilir. Fakat öğrencilerin çevre eğitimindeki kavramlara yönelik bilgilerinin yetersiz olduğu, kavramların anlamlarını bilmedikleri ve bu kavramları tam olarak algılayamadıkları bilinmektedir (Meınhold ve Malkus, 2005; Uzun, Sağlam ve Uzun, 2008; Atasoy ve Ertürk, 2008; Cutter-Mackenzie, 2009; Seçgin, Yalvaş ve Çetin, 2010; Mahidinve Maulan, 2010; Özgen ve Kahyaoğlu, 2011; Ürey, Şahin ve Şahin, 2011). Aynı zamanda öğrencilerin sera etkisi, küresel ısınma, asit yağmurları gibi önemli çevresel problemler konusunda yeterince bilgi sahibi olmadıkları ve çevresel problemlerle ilgili kavramları birbirlerine karıştırdıkları 
http://dx.doi.org/10.23891/efdyyu.2017.20

ISSN:1305-020

belirtilmektedir (Boyes ve Stainsstreet, 1997a,b; Bozkurt ve Aydoğdu, 2004; Bozkurt ve Koray, 2002; Broddy, Chirpmanve Marison, 1988; Darçın, Bozkurt, Hamalosmanoğlu ve Köse, 2006; Kılınç, Stainsstreet ve Boyes, 2008; Meadows ve Wiesenmayer, 1999; Rye, Rubba ve Wiesenmayer, 1997). Bu problemler çevre kavramları ile ilgili farkındalığında bir yönüyle eksik olduğunu ortaya koymaktadır. Yapılan çalışmalar çevre problemleriyle ilgili kavramlarla öğrencilerin çevrelerinde karşılaştıkları gerçek problemler arasında çelişki yaşadıklarını göstermiştir (Dove, 1996; Summers, Kruger ve Childs, 2000; Loughland, Reid ve Petocz, 2002; Shin, 2000). Bu durum, çevre kavramları ile ilgili geliştirilecek olan farkındalık ölçeğinin önemli bir boyut kazandığını göstermektedir. Buradan yola çıkarak, öğrencilerin çevre eğitimi kavramlarına yönelik farkındalıklarını belirlemek için geçerli ve güvenilir bir ölçeğin geliştirilmesi amaçlanmıştır.

\section{Yöntem}

Örneklem: Çalışmanın örneklemini; Bitlis ili merkez ortaokullarının 6., 7. ve 8. sınıflarında öğrenim gören 1140 öğrenci oluşturmaktadır. Çalışmada Açımlayıcı Faktör Analizi (AFA) ve Doğrulayıcı Faktör Analizi (DFA) için ayrı ayrı örneklem grupları oluşturulmuştur. Bu bağlamda, 730 öğrenci ile AFA ve 410 öğrenci ile de DFA yapılmıştır.

Veri Toplama Aracı ve Ölçeğin Geliştirilme Süreci: Çalışmada veri toplamak amacıyla "Çevre Eğitimi Kavramları Farkındalık Ölçeği (ÇEKFÖ)” kullanılmıştır. Ölçek maddeleri oluşturulurken çevre eğitimi kavramlarına ilişkin literatür taranmıştır. İlgili çalışma sonuçları ve ölçme araçları incelenmiş ve 40 maddelik madde havuzu oluşturulmuştur. Ölçekte yer alan önermeler olumlu ve olumsuz ifadeler olacak şekilde düzenlenmiştir. ÇEKFÖ’de yer alan ifadeler öğrencilerin çevre eğitimi kavramları (küresel ısınma, yenilebilir ve yenilemez enerji kaynakları, sera etkisi, asit yağmurları, çevre kirliliği, nüfus artışı v.s) 
http://dx.doi.org/10.23891/efdyyu.2017.20

ISSN:1305-020

farkındalıklarını ortaya çıkaracak şekilde oluşturulmuştur. Ölçek, "Kesinlikle Katılıyorum”, "Katılıyorum", "Kararsızım", "Kesinlikle Katılmıyorum" ve "Katılmıyorum” şeklinde 5 kategorili derecelendirme olarak düzenlenmiştir.

Verilerin Analizi: Ölçeğin güvenirliğinin tespiti için Coronbach Alpha iç tutarlılık katsayısı hesaplanmıştır. Ölçeğin Coronbach Alpha iç tutarlılık katsayısı 0.75 olarak tespit edilmiştir. Geçerlik analizi için ise; kapsam geçerliği, görünüş geçerliği ve yap1 geçerliğine bakılmıştır (Tezbaşaran, 1997). Ölçeğin yapı geçerliliğine ilişkin kanıtlar elde etmek için AFA ve DFA yapılmıştır. Çalışma sırasında geliştirilen ölçekle ilgili ilk olarak AFA yapılmıştır. Elde edilen faktör yapısının test edilmesi için DFA yapılmıştır. Bu amaçla AFA için SPSS 21.0 ${ }^{\mathrm{TM}}$, DFA için Lisrel 8.8 programı kullanılmıştır. Ölçek geliştirme sürecinde, veriler toplanarak istatiksel paket programina girildikten sonra; verilerin tutarlı olup olmadığının incelenmesi, verilerin kontrol edilmesi, ters maddeler varsa düzeltilmesi, kayıp verilerin ve uç değerlerin kontrolü aşamalarının gerçekleştirildikten sonra verilerin çok değişkenli analizler için uygun bir şekle getirilmesi gerekmektedir (Erkuş, 2012). Bu çalışmada; veri girişi, madde istatistikleri ve test istatistikleri SPSS $21.0^{\mathrm{TM}}$ paket programıyla incelenmiştir.

\section{Bulgular}

\section{Verilerin Analizlere Hazırlanması ve AFA Sayıltılarının İncelenmesi}

Denemelik ölçeğe ilişkin geçerlik ve güvenirlik analizlerinden önce veriler üzerinde çok değişkenli analiz sayıltılarıda incelenmiş ve sonrasında denemelik ölçeğe ilişkin madde analizleri ve betimleyici analizler yapılmıştır. Farkındalık ölçeğinin yapı geçerliliğine kanıt sağlamak için faktör analizi (Döndürülmüş Temel Bileşenler Analizi) yapılmıştır (Tabachnick ve Fidell, 2007). Verilerin faktör analizi için uygunluğu Kaiser-Meyer-Olkin (KMO) katsayıs1 ve Barlett Sphericity testiyle incelenmiştir (Büyüköztürk, 2010). KMO katsayısı, verilerin ve 
http://dx.doi.org/10.23891/efdyyu.2017.20

ISSN:1305-020

örneklem büyüklüğ̈̈nün seçilen analize uygun ve yeterli olduğunu belirlemede kullanılan istatistiksel bir yöntemdir. Barlett Sphericity testi ise verilerin çok değişkenli normal dağılımdan gelip gelmediğini kontrol etmek için kullanılabilecek istatistiksel bir tekniktir. Barlett Sphericity testinin anlamlı çıkması veri setinin faktör analizi için verilerin uygun olduğunu göstermektedir (Kalaycı, 2010). Çalışmanın faktör analizine uygun olduğunu gösteren bu test sonucunda Ki-kare değeri ve anlamlılık değeri 0.000 olarak bulunmuştur. Tablo 1' de uygulanan KMO ve Bartlett Testlerinin sonuçlarına ilişkin veriler sunulmuştur.

Tablo 1.KMO ve Bartlett's Testi sonuçlart

\begin{tabular}{lll}
\hline Kaiser-Meyer-Olkin Değeri & & .813 \\
\hline \multirow{3}{*}{ Bartlett Testi Değeri } & Yaklaşık Ki-kare Değeri & 2174.435 \\
\cline { 2 - 3 } & Serbestlik Derecesi & 231 \\
\cline { 2 - 3 } & $\mathrm{p}$ & .000 \\
\hline
\end{tabular}

Tablo 1'e göre, KMO değeri .813 ve Barlett değeri $2174.435(p=.000)$ olarak bulunmuştur. KMO testi, seçilen örneklem verilerinin faktör çıkarmak için uygun olduğunu belirlemektedir. Faktör analizinin yapılabilmesi için KMO değerinin en az 0.60 olması ve BartlettSphericity testinin anlamlı çıkması önerilmektedir (Büyüköztürk, 2010). Barlett katsayısının anlamlı çıkması evrendeki dă̆ılımın normal olduğunun göstergesidir (Tavşancıl, 2002).

\section{Açımlayıcı Faktör Analizine (AFA)İlişsin Bulgular}

Uygulanan faktör analizi sonucunda birden fazla faktöre benzer yük veren ve ölçeğin yapısına uymayan maddelerin çıkartılması sonucunda ölçek son halini almıştır. Ölçeğin son hali 22 maddeden ve 6 faktörden oluşmaktadır. Nihai ölçek formunda yer alan 22 maddeye aitaçıklanan toplam varyansa ait bulgular Tablo 2'de verilmiştir.

Tablo 2. Açıklanan toplam varyans tablosu ve özdeğerleri

\begin{tabular}{|c|c|c|c|}
\hline 尊 & Başlangıç özdeğerleri & Yük değerleri & $\begin{array}{l}\text { Döndürme (rotasyon) } \\
\text { sonrası yük değerleri }\end{array}$ \\
\hline
\end{tabular}


http://dx.doi.org/10.23891/efdyyu.2017.20

ISSN:1305-020

\begin{tabular}{|c|c|c|c|c|c|c|c|c|c|}
\hline & $\frac{\Xi}{\frac{a}{2}}$ & 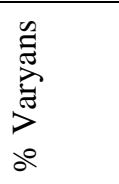 & 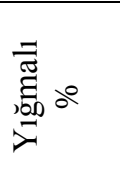 & $\frac{\Xi}{\frac{a}{2}}$ & 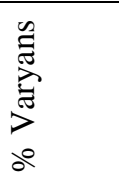 & 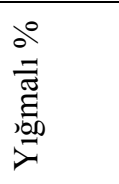 & $\frac{\Xi}{\frac{\Xi}{0}}$ & 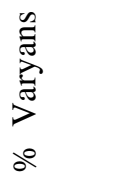 & 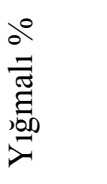 \\
\hline 1 & 3.950 & 17.956 & 17.956 & 3.950 & 17.956 & 17.956 & 2.272 & 10.329 & 10.329 \\
\hline 2 & 1.785 & 8.114 & 26.070 & 1.785 & 8.114 & 26.070 & 1.904 & 8.654 & 18.983 \\
\hline 3 & 1.456 & 6.619 & 32.689 & 1.456 & 6.619 & 32.689 & 1.810 & 8.225 & 27.209 \\
\hline 4 & 1.181 & 5.369 & 38.057 & 1.181 & 5.369 & 38.057 & 1.582 & 7.191 & 34.400 \\
\hline 5 & 1.121 & 5.094 & 43.151 & 1.121 & 5.094 & 43.151 & 1.578 & 7.173 & 41.573 \\
\hline 6 & 1.051 & 4.777 & 47.928 & 1.051 & 4.777 & 47.928 & 1.398 & 6.355 & 47.928 \\
\hline
\end{tabular}

Tablo 2 incelendiğinde, döndürme işlemine tabi tutulan ve varimax tekniği uygulanan ölçeğin 6 faktörüne ilişkin toplam açıklanan varyans1 \%47.928 olup; birinci faktörün ölçeğin \%10.329'unu, ikinci faktörün ölçeğin \%8.654'ini,üçüncü faktörün ölçeğin \%8.225'ini, dördüncü faktörün ölçeğin \%7.191'ini,beşinci faktörün ölçeğin \%7.173'ünü ve altınc1 faktörün ise ölçeğin \%6.355'ini açıkladığı görülmektedir. Maddelere ait faktör yük değerleri Tablo 3' de verilmiştir.

Tablo 3. AFA sonucunda elde edilen faktör yapısı ve faktör yükleri

\begin{tabular}{|c|c|c|c|c|c|c|}
\hline Maddeler & $\begin{array}{c}\text { Faktör } \\
1\end{array}$ & $\begin{array}{c}\text { Faktör } \\
2 \\
\end{array}$ & $\begin{array}{c}\text { Faktör } \\
\mathbf{3} \\
\end{array}$ & $\begin{array}{c}\text { Faktör } \\
4 \\
\end{array}$ & $\begin{array}{c}\text { Faktör } \\
5 \\
\end{array}$ & $\begin{array}{c}\text { Faktör } \\
6 \\
\end{array}$ \\
\hline $\begin{array}{l}\text { Karbondioksit }\left(\mathrm{CO}_{2}\right) \text { gazının artması sera } \\
\text { etkisini artırır. }\end{array}$ & .722 & & & & & \\
\hline $\begin{array}{l}\text { Sera etkisi dünyanın ortalama sıcaklığını } \\
\text { artırır. }\end{array}$ & .692 & & & & & \\
\hline $\begin{array}{l}\text { Ozon tabakasının incelmesi çeşitlikanserlere } \\
\text { sebep olabilir. }\end{array}$ & .612 & & & & & \\
\hline $\begin{array}{l}\text { Asit yağmurlarının sebeplerinden biri de } \\
\text { kentleşmedir. }\end{array}$ & .560 & & & & & \\
\hline $\begin{array}{l}\text { Asit yağmurlarını önlemek için fosil } \\
\text { yakıtlarının kullanımı azaltılmalıdır. }\end{array}$ & .537 & & & & & \\
\hline $\begin{array}{l}\text { Pil, plastik cam, kâğıt gibi atıklar geri } \\
\text { dönüştürülerek tekrar kullanılmalıdır. }\end{array}$ & & .736 & & & & \\
\hline $\begin{array}{l}\text { Çevrenin korunması için geri dönüşümü } \\
\text { sağlanabilecek ürünler tercih edilmelidir. }\end{array}$ & & .723 & & & & \\
\hline $\begin{array}{l}\text { Çevrenin korunmasında çevre eğitiminin } \\
\text { önemi büyüktür. }\end{array}$ & & .593 & & & & \\
\hline $\begin{array}{l}\text { Buzulların erimesi küresel ısınmanın bir } \\
\text { sonucudur. }\end{array}$ & & & .666 & & & \\
\hline $\begin{array}{l}\text { Yenilenemez enerji kaynakları (doğal gaz, } \\
\text { kömür vb.) çevremize zarar verir. }\end{array}$ & & & .618 & & & \\
\hline $\begin{array}{l}\text { Küresel 1sınma iklim değişikliğinin } \\
\text { sebeplerinden biridir. }\end{array}$ & & & .529 & & & \\
\hline Güneş yenilenebilir enerji kaynağıdır. & & & .525 & & & \\
\hline $\begin{array}{l}\text { Kimyasal tarım ilaçları yer altı sularının } \\
\text { kirlenmesine neden olur. }\end{array}$ & & & & .758 & & \\
\hline
\end{tabular}


http://dx.doi.org/10.23891/efdyyu.2017.20

ISSN:1305-020

\begin{tabular}{lc}
\hline \hline Erozyon çevremize zarar verir. & .574 \\
\hline $\begin{array}{l}\text { Nüfus artı̧ı çevre kirliliğinin } \\
\text { sebeplerindendir. }\end{array}$ & .506 \\
\hline $\begin{array}{l}\text { Doğal afetler (deprem, sel vb.) çevreye zarar } \\
\text { verir. }\end{array}$ & .659 \\
\hline $\begin{array}{l}\text { Kimyasal atıklar (ilaçlar, endüstriyel atık vb.) } \\
\text { biyolojik çeşitliliği olumsuz etkiler. }\end{array}$ & .590 \\
\hline Çevre kirlenmesine insanlarda neden olabilir. & .589 \\
\hline $\begin{array}{l}\text { Doğal kaynakların zarar görmesi ekosistemi } \\
\text { olumsuz etkiler. }\end{array}$ & .431 \\
\hline $\begin{array}{l}\text { Küresel ısınma yaşadığımız çevreyi olumlu } \\
\text { etkiler. }\end{array}$ & \\
\hline $\begin{array}{l}\text { Yenilenebilir enerji kaynakları (rüzgâr, } \\
\text { jeotermal vb.) çevre sorunlarına yol açar. }\end{array}$ & .626 \\
\hline Besin zinciri için güneş şart değildir. & .590 \\
\hline
\end{tabular}

Tablo 3'de ölçeğin uygulanmasının ardından elde edilen faktör yüklerinin altı faktör altında toplandığı görülmektedir. Birinci faktör altında 5 madde; ikinci faktör altında 3 madde; üçüncü faktör altında 4 madde; dördüncü faktör altında 3 madde; beşinci faktör altında 4 madde ve altıncı faktörde ise 3 madde yer almaktadır. Elde edilen altı faktördeki maddeler alan uzmanları ile birlikte incelenmiş ve faktörler adlandırılmıştır. Buna göre; birinci faktörün "Sera Etkisi”, ikinci faktörün "İnsan Etkisi”, üçüncü faktörün "Küresel Isınmanın Sebepleri”, dördüncü faktörün "Çevre Kirliliğii”, beşinci faktörün "Çevre Bilinci” ve altıncı faktörün "Çevreyi Korumanın Önemi” olarak adlandırılması kararlaştırılmıştır. Faktör analizi sonrasında elde edilen screeplot grafiği ise Şekil 1'de verilmiştir. 


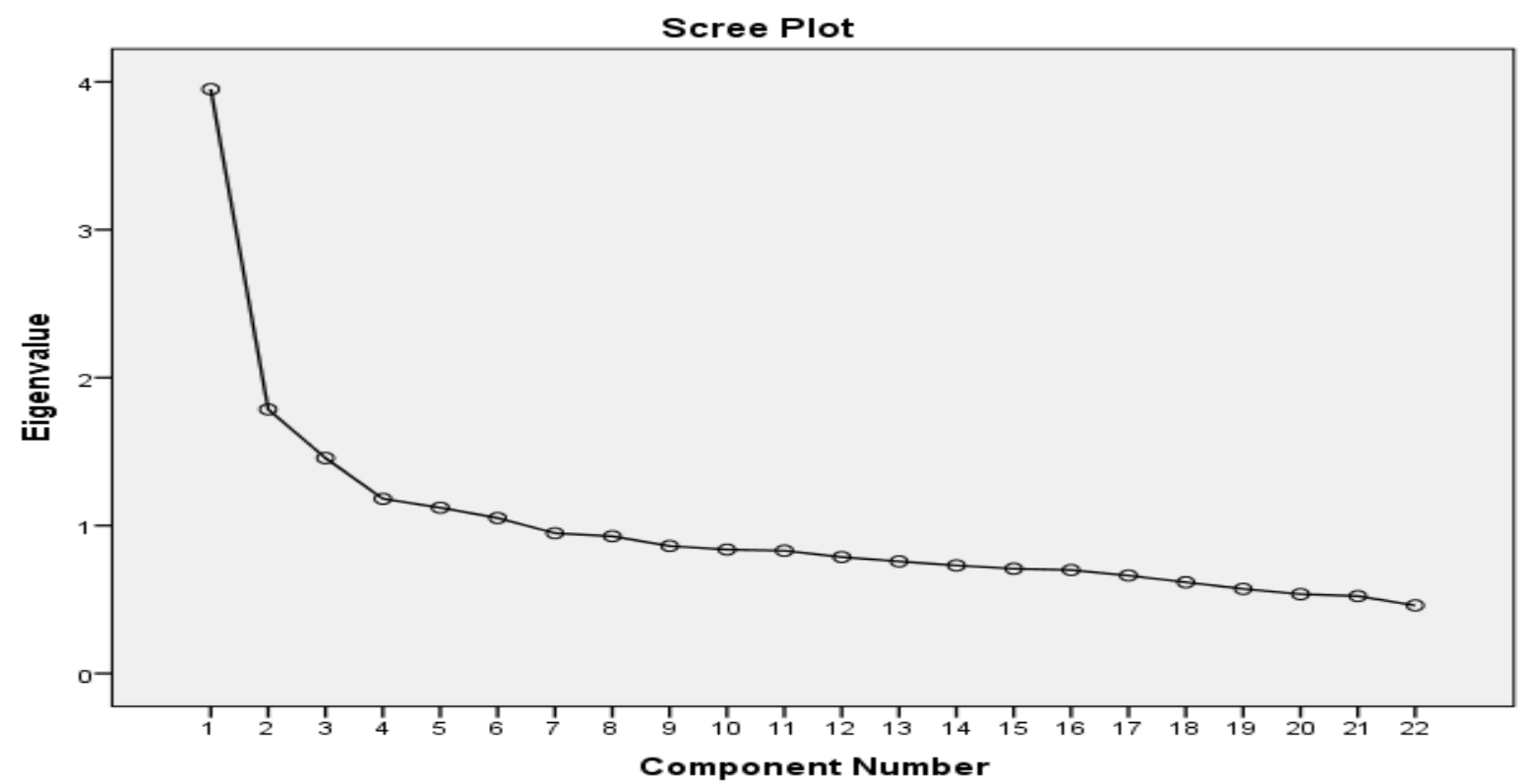

Şekil 1. Scree Plot grafiği

Şekil 1 incelendiğinde, öz değeri 1' den büyük faktör sayısının 6 olduğu görülmektedir.

\section{Doğrulayıcı Faktör Analizine (DFA) İlişkin Bulgular}

Tablo 4' de DAF analizine ilişkin olarak elde edilen uyum indeksleri yer almaktadır.

Tablo 4. Demografik değişkenlere ait tanımlayıcı istatistikler

\begin{tabular}{ll}
\hline Uyumluluk İndeksi & Değerler \\
\hline Serbestlik Derecesi (sd) & 194 \\
\hline Ki-Kare $\left(\mathrm{X}^{2}\right)$ & 367.77 \\
\hline P (p-value) & 0.00 \\
\hline CFI (Comparative Fit Index) & 0.95 \\
\hline GFI (Goodness of Fit Index) & 0.90 \\
\hline AGFI (AdjustedGoodness of Fit Index) & 0.87 \\
\hline IFI (Incremental Fit Index) & 0.95 \\
\hline NFI (Normed Fit Index) & 0.90 \\
\hline NNFI (Non-Normed Fit Index) & 0.94 \\
\hline RMSEA (RootMeanSquareErrorApproximation) & 0.054 \\
\hline RMR(RootMeanSquareResidual) & 0.068 \\
\hline SRMR(StandardizedRootMeanSquareResidual) & 0.060 \\
\hline
\end{tabular}

AFA ile elde edilen 22 maddelik altı faktörlü yapı DFA ile test edilmiştir. Açımlayıcı Faktör Analizi (AFA) sonucu ortaya konan faktör yapısına ilişkin modelin uygunluğu (fit of model), Doğrulayıcı Faktör Analizi (DFA) ile test edilmiştir. Elde edilen modelin uygunluğu, 
http://dx.doi.org/10.23891/efdyyu.2017.20

ISSN:1305-020

RMSEA (Root Mean Square Error Approximation), NFI (Normed Fit Index), NNFI (NonNormed Fit Index), CFI (Comparative Fit Index), IFI (Incremental Fit Index), GFI (Goodness of Fit Index) ve AGFI (Adjusted Goodness of Fit Index) uyum ölçütleri ile test edilmiştir. Yapılan analiz sonucu, modelin uygunluğuna ilişkin RMSEA değeri 0.54; NFI değeri 0.90; NNFI değeri 0.94; CFI değeri 0.95; IFI değer= 0.95; GFI değeri 0.90 ve AGFI değeri 0.87 olarak tespit edilmiştir.CFI ve GFI değerlerinin 0.90’a yaklaşması mükemmel bir modelin habercisi olduğu ilkesinden yola çıkarak, çalışmadaki bu değerlerin iyi bir seviyede olduğu kabul edilebilir. Modelin uygunluğu $X^{2}$ istatistiği tarafından da oldukça anlamlı bulunmuştur $\left(X^{2}=367,77 ; \mathrm{p}<.01\right) . X^{2}$, gözlenen korelasyon matrisinin, kuramsal korelasyon matrisinden ne derecede uzaklaştığının ölçüsünü verir. Düşük $X^{2}$ değeri model ile verinin iyi uyum gösterdiğinin bir ölçüsüdür (Büyüköztürk, 2010). $\quad X^{2} / \mathrm{sd} \leq 5$ veya daha az olması uyumunun iyi olduğunu göstermektedir.

Ölçme modelinin uyum indeksleri incelendiğinde, ilk olarak $\chi^{2}$ değerine ilişkin $p$ düzeyine bakılmıştır. Bu değerin p> .05 olması iyi uyuma işaret etmektedir. Ancak, büyük örneklem gruplarında bu değerin anlamlı $(\mathrm{p}<.05)$ bulunma ihtimali yüksek olduğu için $\chi 2 / \mathrm{sd}$ oranı ve diğer uyum indekslerinin de değerlendirilmesi önerilmiştir (Tabachnick ve Fidell, 2007). Ki-kare değeri $\chi 2=367.77$ ve serbestlik derecesi $\mathrm{sd}=194$ olarak hesaplanmıştır. $\mathrm{Bu}$ değerin 2 ya da 3'ün altında olması iyi uyuma karşılık gelmektedir (Tabachnick ve Fidell, 2007). Bu bağlamda $\chi 2 /$ sd (367.77/194) oranı hesaplanmış ve 1.89 değeri bulunmuştur.GFI indeksi haricinde diğer uyum indekslerinin mükemmel ya da iyi uyum değerleri aldığ belirlenmiştir. Bu durumda faktör yapısı olarak tanımlanan modelin doğrulandığı söylenebilir. DFA sonucunda elde edilen standart değerler ise Şekil 2' de sunulmuştur. 


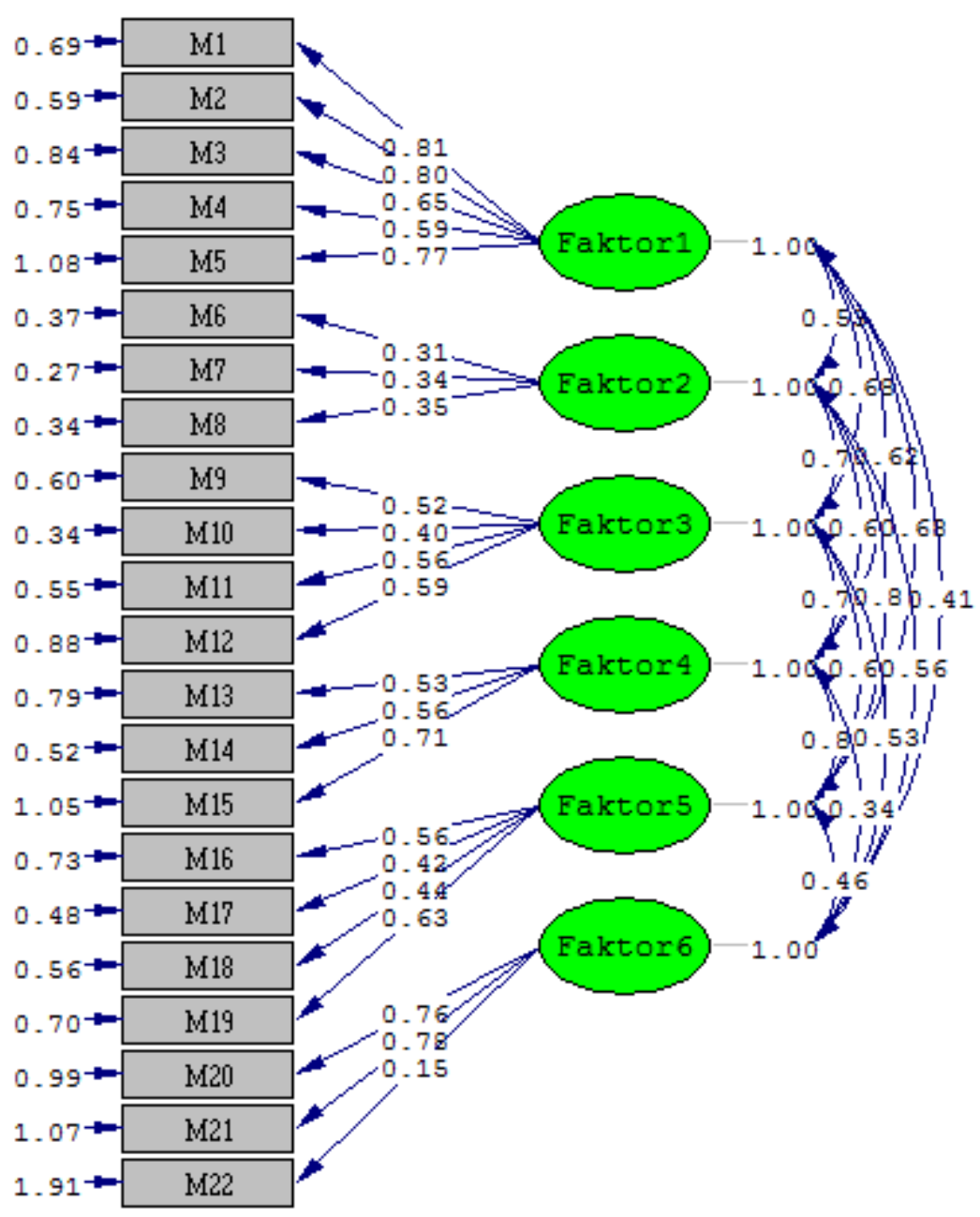

Chi-Square $=367.77, \mathrm{df}=194, \mathrm{P}-\mathrm{value}=0.00000, \mathrm{RMSEA}=0.054$

Şekil 2. DFA analizine ilişkin standartlaştırılmış değerler

Şekilde 2’ deki diyagramda faktör yükleri .15 ile .81 aralığında değişmektedir. Ayrıca analizler sonucunda RMSEA değerinin .054, Ki-kare değerinin 367.7, df değerinin 194 ve p değerinin .000 olduğu görülmektedir. Bu bağlamda, elde edilen sonuçlar yapının doğruluğunu göstermektedir.

\section{Sonuçlar}

$\mathrm{Bu}$ çalışmada ortaokul öğrencilerinin çevre eğitimi kavramlarına yönelik farkındalık düzeylerini belirlemek amacıyla bir ölçek geliştirilmiştir. Geçerlik ve güvenirlik çalışmaları 
http://dx.doi.org/10.23891/efdyyu.2017.20

ISSN:1305-020

tamamlanan "Çevre Eğitimi Kavramları Farkındalık Ölçeği”" ortaokul öğrencilerine uygulanmıştır. Bu çalışma sonucunda, elde edilen geçerlik ve güvenirliğe ait bulgular, ölçeğin ilgiliözelliğe yönelik farkındalıkları belirlemek üzere kullanılabilir nitelikte olduğunu göstermektedir. Ölçeğin 22 maddeden oluşan son halinin faktör analizi için uygunluğunun test edilebilmesi için Kaiser-MeyerOlkin (KMO) katsayısı hesaplanmış ve Barlett'sSphericity testi uygulanmıştır. Elde edilen veriler sonucu ölçeğe faktör analizi yapılabileceği sonucunda ulaşılmıştır. Uygulanan AFA sonucunda ölçek altıfaktörden oluşmaktadır ve \% 47.928 varyans açıklama yüzdesine sahiptir. Elde edilen faktörler " $F_{1}$ : Sera Etkisi”, " $F_{2}$ : İnsan Etkisi”, "F $F_{3}$ : Küresel Isınmanın Sebepleri”, " $F_{4}$ : Çevre Kirliliği”, " $F_{5}$ : Çevre Bilinci” ve "F $F_{6}$ : Çevreyi Korumanın Önemi” olarak isimlendirilmiştir. Ölçeğin tamamının Cronbach’s Alpha içtutarlılık katsayısı ise $0.75^{\prime}$ dir. AFA sonucu ortaya konan modelin uygunluğu DFA ile test edilmiştir. Elde edilen uyum değerlerine göre model uyumluluğu istatistiksel olarak kabul edilebilir düzeydedir.

Geliştirilen ölçek benzer özelliklere sahip farklı örneklemdeki öğrencilerinin farkındalıklarını belirlemek için de kullanılabilir. Ölçek bunun dışındaki grupların çevre kavramlarına yönelik farkındalıklarını belirlemek için kullanılacaksa, o gruplardan elde edilecek verilerle geçerlik ve güvenirlik çalışmasının tekrar yapılarak kullanımı önerilmektedir. Çalışmanın önemli bir sınırlılığı Bitlis il merkezindeki ortaokullarının 6., 7. ve 8. sınıf öğrencileri ile sınırlandırılmış olmasıdır. Bu konuda daha kesin ve genel sonuçlara ulaşabilmek için araştırma Türkiye genelinde yer alan diğer ortaokul öğrencilerine de uygulanabilir. Ayrıca, çalışmada sadece nicel yöntemler kullanılarak toplanmıştır. Örneklem grubu ile yapılacak olan görüşmelerle de elde edilecek nitel veriler sonucu çalışma desteklenebilir.

\section{Makalenin Bilimdeki Konumu (Yeri)}


http://dx.doi.org/10.23891/efdyyu.2017.20

Fen Bilgisi Eğitimi Anabilim Dalı/Çevre Eğitimi

ISSN:1305-020

\section{Makalenin Bilimdeki Özgünlüğü}

Çevre eğitimi, çevreye yönelik farkındalık meydana getirme sürecinde büyük bir öneme sahiptir. Çevre eğitiminde asıl amaç ise, çevre problemleriyle ilgili bilgi sahibi olan, bu problemleri çözmede nasıl bir katkısı sağlayabileceğinin ve çevre kavramlarının farkında olan bireyler yetiştirmektir (Xuehua, 2004; Waktola, 2009; Solmaz, 2010). Çevre problemlerinin çözülmesi, insanların problemleri algılaması ve risklerinin farkında olması ile aşılabilecektir (Vaizoğlu ve Altıntaş, 2005).Yapılan çalışmalar çevre problemleriyle ilgili kavramlarla öğrencilerin çevrelerinde karşılaştıkları gerçek problemler arasında çelişki yaşadıklarını göstermiştir (Dove, 1996; Summers, Kruger ve Childs, 2000; Boyes ve Chambers, 1995; Loughland, 2002; Shin, 2000). Bu durumun çevre kavramları ile ilgili geliştirilecek olan farkındalık ölçeğinin önemli bir boyut kazandığını göstermektedir. Buradan yola çıkarak, öğrencilerin çevre eğitimi kavramlarına yönelik farkındalıklarını belirlemek için geçerli ve güvenilir bir ölçeğin geliştirilmesi amaçlanmıştır.

\section{Kaynaklar}

Atasoy, E. ve Ertürk, H. (2008). İlköğretim öğrencilerinin çevresel tutum ve çevre bilgisi üzerine bir alan araştırması. Erzincan Eğitim Fakültesi Dergisi, 10(1), 105-122.

Büyüköztürk, Ş. (2010). Sosyal bilimler için çok değişkenli istatistik (6. Baskı). Ankara: PegemAkademi Yayıncılık.

Brown, T. A. (2006). Confirmatory factor analysis for applied research. New York, NY: Guilford Press. 
http://dx.doi.org/10.23891/efdyyu.2017.20

ISSN:1305-020

Boyes, E. \& Stainesstreet, M. (1997a). Childrens' models of understanding of two major global environmental 1ssues (Ozone layer and greenhouse effect). Research in Science \& Technological Education, 15(1), 19-28.

Boyes, E. \& Stanisstreet, M. (1997b). The environmental impact of cars. Environmental Education Research, 3(3), 269- 282.

Bozkurt O. ve Aydoğdu M. (2004). İlköğretim öğrencilerinin “ozon tabakası ve görevleri” hakkındaki kavram yanılgıları ve oluşturma şekilleri. Kastomonu Eğitim Dergisi, 12(2), 369-376.

Bozkurt, O. ve Koray, Ö. (2002). İlköğretim öğrencilerinin çevre eğitiminde sera etkisi ile ilgili kavram yanılgıları. Hacettepe Üniversitesi Ĕ̆itim Fakültesi Dergisi, 23, 67-73.

Broody, M., Chirpman, E. \& Marion, S. (1988). An assesment of student knowledge in fourth, eight and eleventh grades of science and natural resource concepts related to acidic deposition. Educational Resources Information Center (ERIC) Document, ED: 291551.

Cutter-Mackenzie, A. (2009). Multicultural school gardens: creating engaging garden spaces in learning about language, culture, and environment. Canadian Journal of Environmental Education, 14, 122-135.

Darçın, E.S., Bozkurt, O., Hamalosmanoğlu, M. ve Köse, S. (2006). Misconceptions about Greenhouse Effect. International Journal of Environmental \& Science Education, 1(2), 104-115.

Dove, J. (1996). Student teacher understanding of the greenhouse effect, ozone layer depletion and acid rain. Environmental Education Research, 2, 89-100.

Erkuş, A. (2012). Psikolojide ölçme ve ölçek geliştirme (1. Baskı). Ankara: PegemAkademi Yayınları. 
http://dx.doi.org/10.23891/efdyyu.2017.20

ISSN:1305-020

Eulefeld, G. (1979). The UNESCO-UNEP programme in environmental education. International Journal of Science Education, 1(1), 113-118.

Hooper, D., Coughlan, J. \& M. Mullen. (2008). "Structural equation modelling: guidelines for determining model fit. "Electronic Journal of Business Research Methods, 6 (1), 5360.

Hu, L. T. \& Bentler, P.M. (1999). “Cutoff criteria for fit indexes in covariance structure analysis: conventional criteria versus new alternatives. "Structural Equation Modeling: A Multidisciplinary Journal, 6 (1), 1-55.

Kalaycı, Ş. (2010). SPSS Uygulamalı çok değişkenli istatistik teknikleri. Ankara: Asil Yayın.

Kayaer, M., (2013). Çevre ve etik yaklaşımlar. Siyaset, Ekonomi ve Yönetim Araştırmaları Dergisi, Sakarya Üniversitesi, 1(2).

Kline, R. B. (2011). Principles and Practice of Structural Equation Modeling. 3rd ed. New York: Guilford.

Kılınç, A., Stainsstreet, M. ve Boyes, E. (2008). Turkish students' about global warming. International journal of Environmental \& Science Education, 3 (2), 89-98.

Loubser, C. P. \& Ferreira, J. G. (1992). Environmental education in south africa in light of the tbilisi and moscow conferences. The Journal of Environmental Education, 23(4), 31-34.

Loughland, T., Reid, A. \& Petocz, P. (2002). Young people's conceptions of environment: Aphenomenographic analysis. Environmental Education Research, 8(2), 187-197.

Mahidin, A.M.M. \& Maulan, S. (2010). Understanding children preferences of natural environment as a start for environmental sustainability. Procedia - Social and Behavioral Sciences, 38, 324 - 333. 
http://dx.doi.org/10.23891/efdyyu.2017.20

ISSN:1305-020

Meadows, G. \& Wiesenmayer, R., L. (1999). Identifying and addressing students' alternative conceptions of the causes of global warming: The need for cognitive conflict. Journal of Science Education and Technology, 8(3), 235-239.

Meınhold, J.L. \& Malkus, A.J. (2005). Can knowledge, attitudes, and self-efficacy make a difference? Environment And Behavior, 37(4), 511-532.

Rye, J., Rubba, P. \& Wiesenmayer, R.(1997). An investigation of middle school students' conceptions of global warming.International Journal of Science Education, 19(5), 527551.

Shin, D. S. (2000). Environmental education course development for preservice secondary school science teachers in the Republic of Korea. The Journalof Environmental Education. 31(4), 11- 18

Solmaz, G. (2010). İşbirlikli öğrenme yoluyla kavramsal anlamaya yönelik öğretimin öğrencilerin çevre kavramlarını anlamalarına ve çevre farkındalıklarına etkisi:7. Sınıf “İnsan ve Çevre” Ünitesi Örneği. Dokuz Eylül Üniversitesi, Yüksek Lisans Tezi, İzmir.

Summers, M., Kruger, C. \& Childs, A. (2000). Primary school teachers' understanding of environmental issues: An interview study. Environmental EducationResearch, 6 (4), 293-312.

Şama, E. (2003). Öğretmen adaylarının çevre sorunlarına yönelik tutumları. G. Ü. Gazi Ĕ̆gitim Fakültesi Dergisi, 23(2), 99-110.

Seçgin, F. Yalvaş, G. ve Çetin, T. (2010). İlköğretim 8. sınıf öğrencilerinin karikatürler aracılığıyla çevre sorunlarına ilişkin algıları. International Conference on New Trends in Education and Their Implications, 11-13 November, Antalya-Turkey, 391-398.

Tabachnick, G. G. \& Fidell, L.S. (2007). Experimental Designs using ANOVA. Belmont, CA: Duxbury. 
http://dx.doi.org/10.23891/efdyyu.2017.20

ISSN:1305-020

Tavşancıl, E. (2002). Tutumların Ölçülmesi ve SPSS ile Veri Analiz. Ankara: Nobel Yayın Dağıtım.

Tezbaşaran, A. A. (1997). Likert tipi ölçek geliştirme kulavuzu (2. bs.). Ankara: Türk Psikologlar Derneği Yayınları.

Thompson, B. (2008). Exploratory and confirmatory factor analysis: understanding concepts and applications. 3rd ed. Washington, DC: American Psychological Association.

Özdemir, O. Yıldız, A., Ocaktan, E. ve Sarışen, Ö. (2004). Tıp fakültesi öğrencilerinin çevre sorunları konusundaki farkındalık ve duyarlılıkları. AnkaraÜniversitesi Tıp Fakültesi Dergisi, 57(3), 117.

Özgen, N. ve Kahyaoğlu, M. (2011). Farklı fonksiyonel özeliğe sahip yerleşim ünitelerinde ikamet eden ilköğretim öğrencilerinin çevre sorunlarını algılama ve çözüm önerileri: Fenomenografik bir araştırma. Elektronik Sosyal Bilimler Dergisi, 10(38), 136-157.

Solmaz, G. (2010). İşbirlikli öğrenme yoluyla kavramsal anlamaya yönelik öğretimin öğrencilerin çevre kavramlarını anlamalarına ve çevre farkındalıklarına etkisi: 7.sınıf “insan ve çevre” ünitesi örneği. Yüksek lisans tezi, Dokuz EylülÜniversitesi, İzmir.

Sümer, N. (2000). Yapısal eşitlik modelleri: Temel kavramlar ve örnek uygulamalar. Turkish Psychological Articles, 3(6), 49-74.

Uzun, N., Sağlam, N. ve Uzun, F.V. (2008). Yeşil sınıf modeline dayalı uygulamalı çevre eğitimi projesinin çevre bilinci ve kalıcılığına etkisi. Ege Ĕ̆itim Dergisi, 9(1), 59-74.

Ürey, M., Şahin, B. ve Şahin, N. F. (2011). Öğretmen adaylarının temel ekoloji kavramları ve çevre sorunları konusundaki yanılgıları. Ege Üniversitesi Eğitim Fakültesi Dergisi, 12(1), 22-51. 
http://dx.doi.org/10.23891/efdyyu.2017.20

ISSN:1305-020

Vaizoğlu, S. ve Altıntaş, H. (2005). Bir tıp fakültesi son sınıf öğrencilerinin çevre bilincinin değerlendirilmesi. TSK Koruyucu Hekimlik Bülteni, 4(4), 151- 171.

Waktola, D.K. (2009). Challenges and opportunities in mainstreaming environmental education into the curricula of teachers' colleges in Ethiopia. Environmental Education Research, 15(5), 589-605.

Xuehua, Z. (2004). An Overview of the environmental knowledge system for elementary school students. Chinese Education and Society, 37(4), 45-47. 